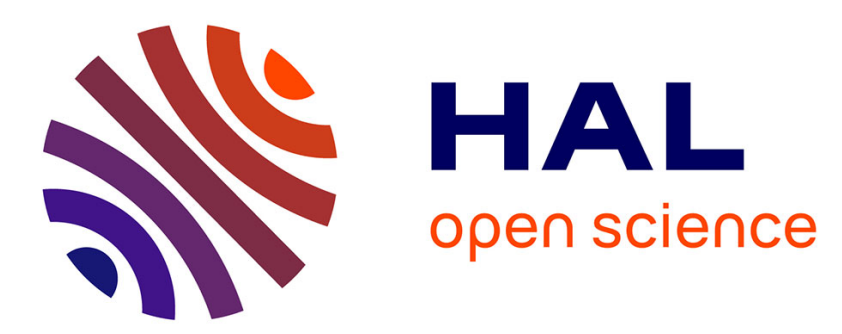

\title{
High Speed Blanking: An Experimental Method to Measure Induced Cutting Forces
}

Camille Gaudilliere, Nicolas Ranc, Arnaud Larue, A Maillard, Philippe Lorong

\section{To cite this version:}

Camille Gaudilliere, Nicolas Ranc, Arnaud Larue, A Maillard, Philippe Lorong. High Speed Blanking: An Experimental Method to Measure Induced Cutting Forces. Experimental Mechanics, 2013, 53 (7), pp.1117-1126. 10.1007/s11340-013-9738-1 . hal-00986953

\section{HAL Id: hal-00986953 https://hal.science/hal-00986953}

Submitted on 6 May 2014

HAL is a multi-disciplinary open access archive for the deposit and dissemination of scientific research documents, whether they are published or not. The documents may come from teaching and research institutions in France or abroad, or from public or private research centers.
L'archive ouverte pluridisciplinaire HAL, est destinée au dépôt et à la diffusion de documents scientifiques de niveau recherche, publiés ou non, émanant des établissements d'enseignement et de recherche français ou étrangers, des laboratoires publics ou privés. 


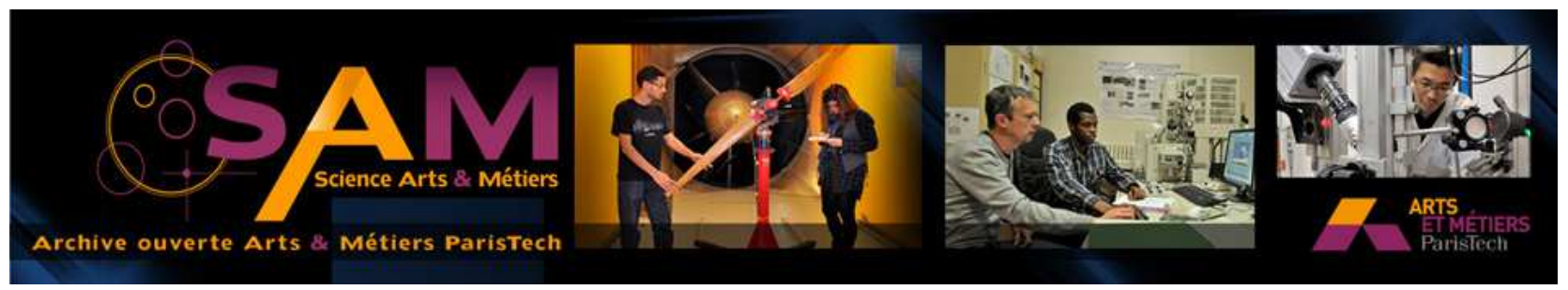

Science Arts \& Métiers (SAM)

is an open access repository that collects the work of Arts et Métiers ParisTech researchers and makes it freely available over the web where possible.

This is an author-deposited version published in: http://sam.ensam.eu Handle ID: .http://hdl.handle.net/10985/8094

\section{To cite this version :}

Camille GAUDILLIERE, Nicolas RANC, Arnaud LARUE, A MAILLARD, Philippe LORONG - High Speed Blanking: An Experimental Method to Measure Induced Cutting Forces - Experimental Mechanics - Vol. 53, n7, p.1117-1126 - 2013 


\title{
High Speed Blanking: An Experimental Method to Measure Induced Cutting Forces
}

\author{
C. Gaudillière $\cdot$ N. Ranc $\cdot$ A. Larue $\cdot$ A. Maillard . \\ P. Lorong
}

\begin{abstract}
A new blanking process that involves punch speed up to $10 \mathrm{~ms}^{-1}$ has obvious advantages in increased productivity. However, the inherent dynamics of such a process makes it difficult to develop a practical high speed punch press. The fracture phenomenon governing the blanking process has to be well understood to correctly design the machine support and the tooling. To observe this phenomenon at various controlled blanking speeds a specific experimental device has been developed. The goal is to measure accurately the shear blanking forces imposed on the specimen during blanking. In this paper a new method allowing the blanking forces to be measured and taking into account the proposed test configuration is explained. This technique has been used to determine the blanking forces experienced when forming $\mathrm{C} 40$ steel and quantifies the effect of process parameters such as punch die clearance, punch speed, and sheet metal thickness on the blanking force evolution.
\end{abstract}

Keywords High speed blanking · Blanking force measurement · Hopkinson device

C. Gaudillieère · N. Ranc $(\bowtie) \cdot$ A. Larue $\cdot$ P. Lorong Arts et Métiers ParisTech, PIMM, UMR CNRS 8006, 151 Boulevard de l'Hôpital, 75013 Paris, France e-mail: nicolas.ranc@ensam.eu

URL: http://pimm.paris.ensam.fr/en/user/9

\section{Introduction}

Blanking is a shearing process which is commonly used in the metal forming industry [1-3]. Using this process, large and very large production runs of thin parts can be manufactured from sheet metal stock. Currently, two main blanking technologies exist: traditional blanking and fine blanking. In traditional blanking the sheet metal is located on the die and the punch blanks it to obtain the desired workpiece geometry. The punch speed and the clearances between the punch and the die are about $0.1 \mathrm{~ms}^{-1}$ and $10 \%$ of the metal sheet thickness. In the fine blanking process the metal sheet is compressed between the die and a guide plate. An upper and a lower punch extract the workpiece. In this technique, the punch speed and the clearances between punch and die are lower: about $0.01 \mathrm{~ms}^{-1}$ for the punch speed and $1 \%$ for the clearances. The main advantages of fine blanking are the tight tolerances and also the elimination of finishing machining operations. However, the tool costs are higher than the conventional blanking technique.

The constant improvement of the technology of the presses and particularly of hydraulic actuators allows an increase in punch speed. It is thus possible to develop high speed blanking with a punch speed of about $10 \mathrm{~ms}^{-1}$. Research and industrial experiments show that high speed blanking has many potential advantages, especially the possibility to obtain a high quality blanking edge geometry, comparable to those obtained from the fine blanking technique. The new process also reduces the zone affected by plastic strain. This allows a reduction in the distance between each workpiece and a consequent saving in materials. With high speed blanking, unlike fine blanking, heat treatments such as spheroidizing for carbon steel are not necessary. Furthermore, the technique does not require the use of lubricant. 
Nevertheless, a general lack of experience with the process tend to lead to short tool life and poor prediction of the geometrical and dimensional quality of the product. The tooling has to be better designed to produce parts in a way that satisfies industrial requirements. Tooling design is a crucial part of the development of such a process, and necessitates a reliable estimation of the cutting forces. This study aims to measure these forces.

The first attempt to increase punch speed to reduce the blanking energy was undertaken by Zener and Hollomon in 1944 [4]. Many studies were carried out thereafter to determine the effect of the punch speed and punch die clearance on blanking energy [5-9]. These different works established the link between the reduction in blanking energy when the punch speed is increased and the occurrence of adiabatic shear bands [10]. Some of the studies focused on the determination of the evolution of blanking forces during the process [11-13]. Measurement of blanking forces was carried out with the Hopkinson bar or tube system. However, the effect of process parameters, materials choice and the geometry of the tools on the history of the blanking force are still not well described and the experimental methods used are difficult. Knowledge of these blanking forces is necessary to design tools and to identify and predict the nature of the fracture mechanisms in a precise and useful way.

The objective of this work is to propose and test an experimental technique which enables the estimation of the blanking forces by taking into account the dynamic contribution of the three-dimensional geometry of the die. These blanking forces data will allow the characterization of the effect of parameters such as punch speed, blanking sheet metal thickness and the clearance between punch and die.

The second part of the paper describes the proposed experimental device. The results of a typical test are presented. The third part of the paper discusses in detail the method used to determine the blanking induced forces. The last part shows and discusses the effects of punch speed variation on blanking force.

\section{High Speed Blanking Tests}

\section{The Loading Device and Measurement}

To reach very high speeds during blanking process, a specific experimental device, which allows the measurement of the cutting forces and observation the shear zone was designed and built. This device which is shown in Fig. 1(a), can be divided into three component parts. The "punch impulse device" is a punch propelled by an air gun. This device contains a hydraulic control system allowing the user to adapt the pressure in the air receiver of the air gun to produce the desired launching speed. A linear guide system enables precise control of the gap between the cutting punch flanks and the workpiece cut faces. The general geometry of the punch is detailed in Fig. 1(d). The
Fig. 1 Scheme of the experimental device (a) general view, (b) enlargement on the active zone, (c) specimen, (d) geometry of the punch

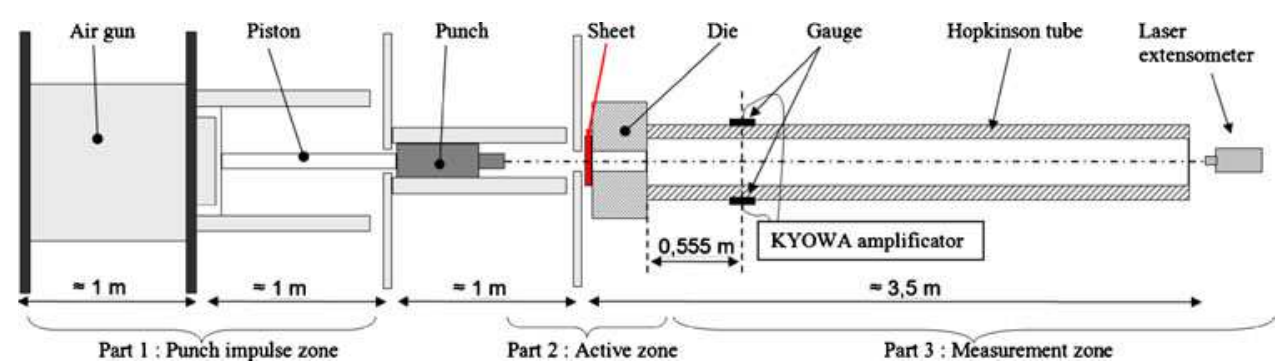

(a)

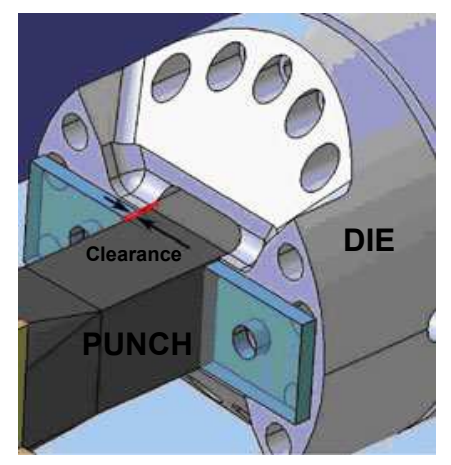

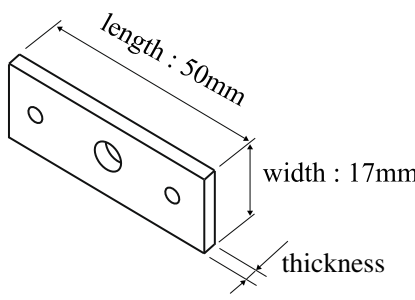

(c)

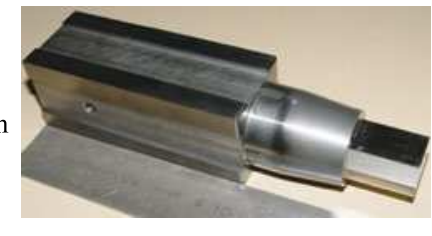

(d) (b) 
second part is the "active zone" and is composed of a die with a mass of $1.4 \mathrm{~kg}$ (Fig. 1(b)) which supports the specimen before and during the blanking action. The test specimens are rectangular milled sheets of metal with a thickness of $2 \mathrm{~mm}, 3 \mathrm{~mm}$ or $4 \mathrm{~mm}$ with an accuracy to within $0.02 \mathrm{~mm}$. The general shape of the specimen is shown in Fig. 1(c). The width is $17 \mathrm{~mm}$ and length is $50 \mathrm{~mm}$. By changing the die, the clearance can be set to $0.05 \mathrm{~mm}$ or $0.2 \mathrm{~mm}$. A stop-system has been designed to stop the punch just after blanking to avoid any direct interference between the punch and the die. In the last part of the rig, the "the measurement device", the cutting forces are estimated using a Hopkinson tube device. The section of the Hopkinson tube noted $S_{\text {tube }}$ is about $6.28 \times 10^{-4} \mathrm{~m}^{2}$ and length is $3.5 \mathrm{~m}$. The tube is made from 100C6 steel with a Young's modulus $E_{\text {tube }}=206 \mathrm{MPa}$ and a density $\rho_{\text {tube }}=7800 \mathrm{MPa}$. The impedance of the tube defined as $Z_{\text {tube }}=S_{\text {tube }} \sqrt{\rho_{\text {tube }} E_{\text {tube }}}$ is about $2.6 \times 10^{4}$ Pa.s.m.

The strain wave generated in the Hopkinson tube by the cutting process is measured using strain gages. The location of the gages on the tube and the remaining length on the tube allows measurement duration of $1.2 \mathrm{~ms}$ without overlapping of the signal on the gages. The bandwidth of the gage amplifier is about $500 \mathrm{kHz}$. A laser extensometer with a bandwidth of $250 \mathrm{kHz}$ (manufacturer: Polytec; model: HSV-2000 series) is located at the end of the tube targets the front face of the punch through a hole drilled in the center of the sample and measures the speed. The radius of the hole is about $1 \mathrm{~mm}$ and the distance between the hole and the shear zone is quite large $(8 \mathrm{~mm})$. Moreover the plastic strain due to the punching process remains very close to the shear zone. The punch speed and the Hopkinson tube strain signals are recorded by a data acquisition system with a sampling frequency of $1 \mathrm{MHz}$.

A high speed blanking test can be separated into different steps. First, the pressure increases in the air gun compressor tank (step 1). Then, when the test is activated, the air tank is opened and propels the piston and the punch (step 2). In the third step, the piston is stopped and the punch flies freely along the punch guides. In the step 4, the punch cuts the specimen. Finally, the punch is stopped and the cut part of the specimen is ejected into the Hopkinson tube.

\section{Blanking Test Results}

Tests were carried out with a fixed clearance between die and punch equal to $0.05 \mathrm{~mm}$ and an initial punch speed between $7 \mathrm{~ms}^{-1}$ and $18 \mathrm{~ms}^{-1}$. The punch mass is equal to $1.5 \mathrm{~kg}$. The specimen has a parallelepipedal geometry with dimensions: $17 \mathrm{~mm}$ width, $50 \mathrm{~mm}$ length and $2 \mathrm{~mm}, 3 \mathrm{~mm}$ or $4 \mathrm{~mm}$ thickness (Fig. 1(c)). The specimen material is a $\mathrm{C} 40$ steel with the composition given in Table 1.
Table 1 Metallurgical composition of the C40 steel

\begin{tabular}{lllllll}
\hline & $\mathrm{C}$ & $\mathrm{Mn}$ & $\mathrm{Si}$ & $\mathrm{P}$ & $\mathrm{S}$ & $\mathrm{Mo}$ \\
\hline Weight $\%$ & $0.35 \pm 0.4$ & $0.65 \pm 0.15$ & 0.4 & 0.035 & 0.035 & 0.10 \\
\hline
\end{tabular}

Figure 2(a) shows the change in punch speed with time during a blanking test on a specimen with a $2 \mathrm{~mm}$ thickness. The first phase corresponds to the punch propulsion phase where the punch speed increases quasi linearly. Then, when the piston is stopped, the punch slips freely along the guide rails. The speed decreases slightly because of friction. At the beginning of the cut, the punch strikes the specimen front face and the speed decreases very quickly. Just after the cut the punch moves again before finally stopping. Then the punch speed oscillates around zero with possibly a small negative mean speed due to punch rebound.

Figure 2(b) is an enlargement of Fig. 2(a) of the cutting duration shows the decrease and the oscillation of the punch front face during blanking. The oscillations of the punch speed are strongly characterized by a dominating harmonic frequency of about $20 \mathrm{kHz}$. This frequency corresponds to the first longitudinal eigen frequency of the punch. For the test shown in this Fig. 2(b), the punch speed before the cut is equal to $11.5 \mathrm{~ms}^{-1}$ and at the end of the cut, the punch speed oscillates around a constant value which is estimated at $9.4 \mathrm{~ms}^{-1}$. It is also possible to calculate the cutting energy which is assumed to be equal to the variation of the kinetic energy of the punch. In the case of the test conducted at a punch speed of $11.5 \mathrm{~ms}^{-1}$ the calculated blanking energy is $33 \mathrm{~J}$. It is possible from Fig. 2(b) to estimate the cutting time which corresponds to the duration of the speed decreasing phase, and the mean blanking force can also be determined. The estimated blanking time and the mean blanking force are equal to $220 \mu \mathrm{s}$ and $14 k N$.

This method becomes difficult to apply when the blanking duration is small i.e. when the punch speed is high or when the thickness of the specimen is small. Moreover this method only gives an estimate of the mean blanking forces during the cut. The blanking forces are also determined from the Hopkinson tube device. Figure 3 shows the strain measurements from the Hopkinson tube gages during the same test. This signal shows a compressive stress in the tube resulting from the blanking forces on the die. The origin of the timescale corresponds to the beginning of the cut. The delay of $135 \mu \mathrm{s}$ between the beginning of the cut and the decrease of the strain is due to the wave propagation between the die and the gages on the Hopkinson tube. The loading duration at the half amplitude is about $79 \mu s$ and the maximum longitudinal strain in the Hopkinson tube is about $240 \times 10^{-6}$. For a tube section of $S_{\text {tube }}=6.28 \times 10^{-4} \mathrm{~m}^{2}$ and a Young's modulus for the 
Fig. 2 Punch speed variation during a cutting test (C40 Steel; initial speed: $11.5 \mathrm{~ms}^{-1}$; thickness: $2 \mathrm{~mm}$; clearance: $0.05 \mathrm{~mm})$ (a) general view (b) enlargement during the cut

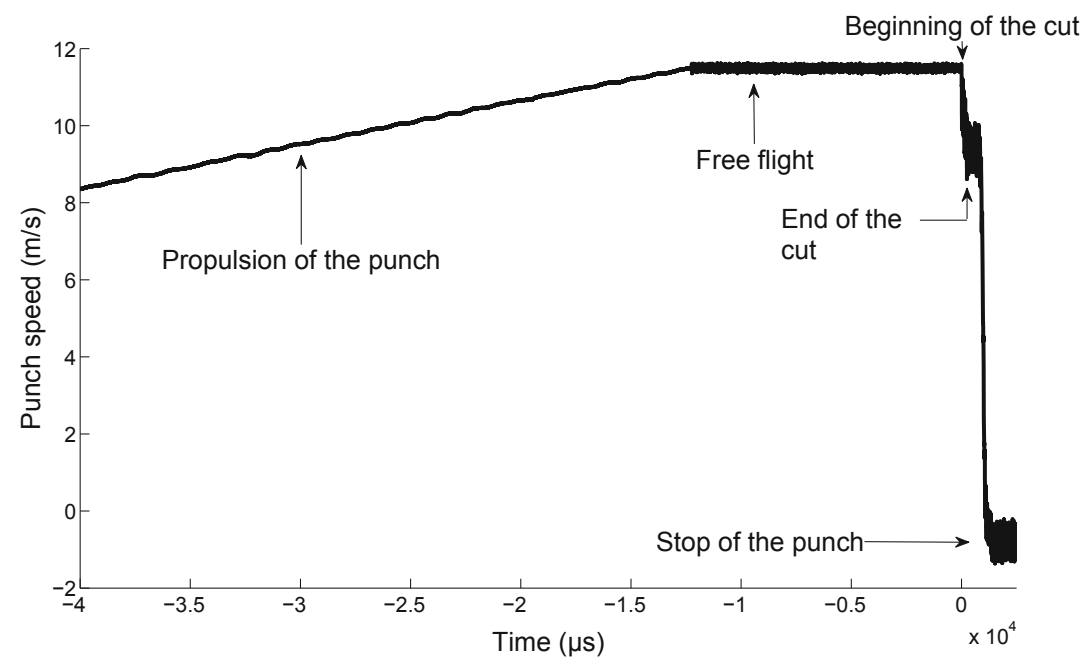

(a)

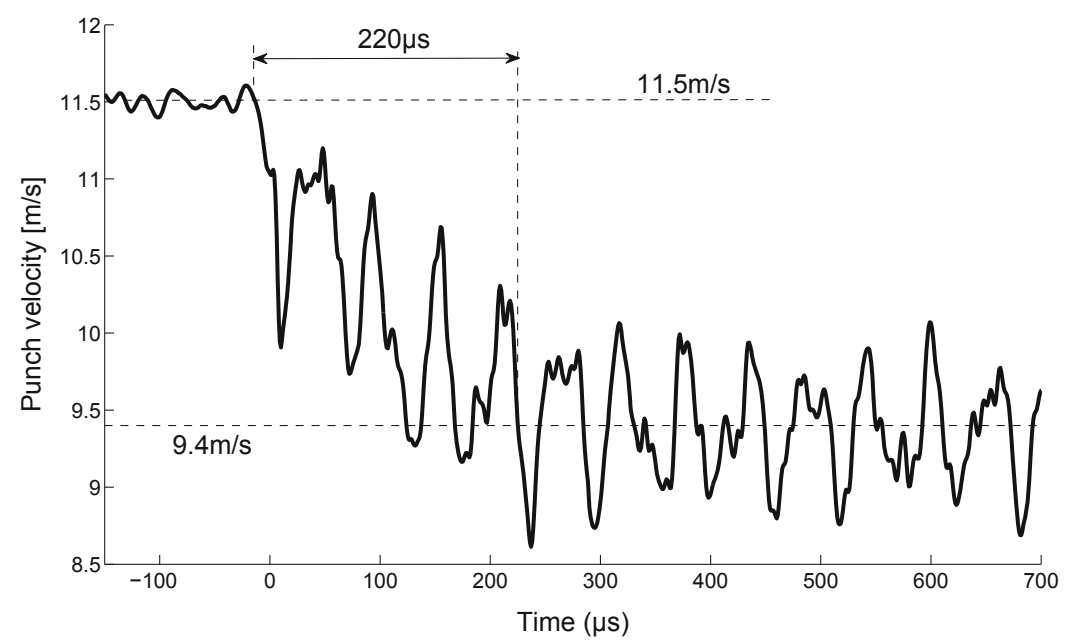

(b) tube material of $E_{t u b e}=206 \mathrm{GPa}$ (mild steel), this strain value corresponds to a maximum force in the tube of $31 \mathrm{kN}$. This value can be different from the maximum cutting force because the complex die geometry and the die tube interface perturbs elastic wave propagation. This problem will be discussed in the next section.
Fig. 3 Evolution of the measured strain on the Hopkinson tube $\varepsilon_{m}$ versus time

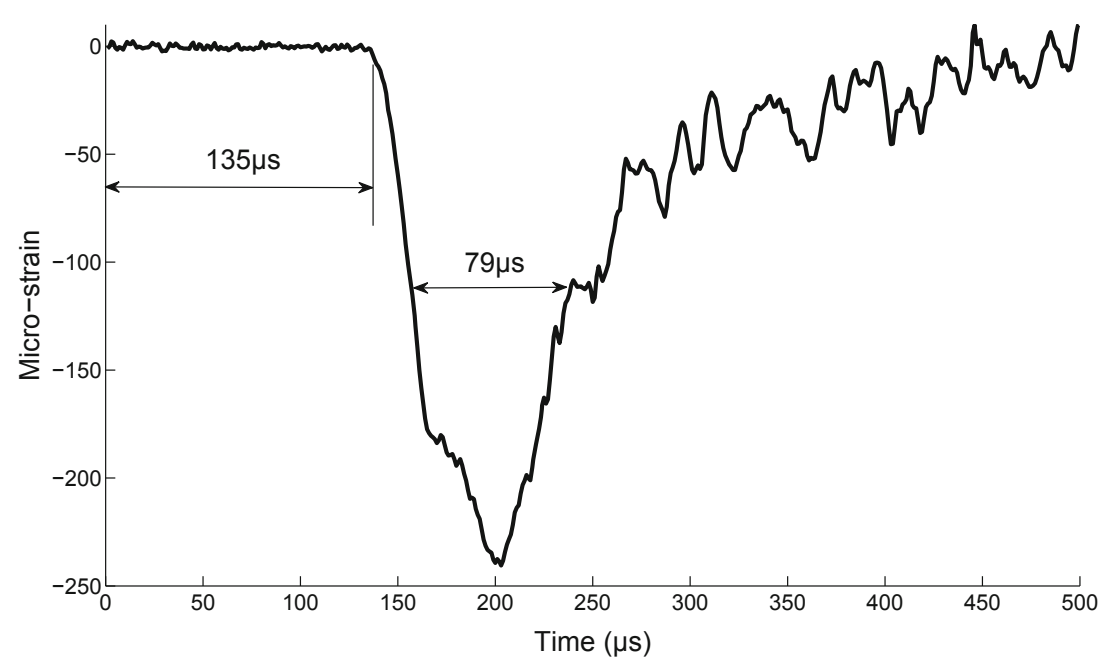




\section{Determination of the Blanking Forces}

\section{Calibration of the Blanking Forces Measurement Device}

In our experimental device, the strain gage enables the estimation of the forces in the Hopkinson tube induced by the blanking process. The one-dimension elastic wave theory which is often used in the Hopkinson bar technique could not be used in this study because of the complex 3D geometry of the die. The die has been designed to be as much as possible like an industrial die. To estimate the blanking forces, our device was calibrated to make a link between blanking forces on the die and the strains measured on the Hopkinson tube.

The main difficulty in calibrating the device is how to apply a known force with a controlled amplitude and a duration similar to that of the blanking forces: the loading duration of a blanking test can vary between 35 and $400 \mu s$. As a consequence, another Hopkinson apparatus was chosen (Fig. 4). Two projectiles of $68 \mathrm{~mm}$ and $132 \mathrm{~mm}$ allow a controlled pulse duration of respectively 30 and $52 \mu s$. The loading amplitude is controlled by the projectile speed. To limit bending in the incident bar, the projectiles have a rounded end. Using this experimental device an incident cylindrical bar in 100C6 steel with a diameter of $32 \mathrm{~mm}$ is inclined against the die in a similar fashion to the specimen during the cut. The impedance of the incident bar is $3.2 \times 10^{4}$ Pa.s.m. A gage placed on the incident bar is used to measure the longitudinal strain in this bar. When the projectile impacts against the incident bar, a compressive wave is created in the calibration bar which propagates up to the die. At the interface the wave is split into a reflected and a transmitted wave which are respectively measured with the gages $J_{i}$ and $J_{\text {tube }}$. The applied force noted $F_{\text {calib }}$ on the die is expressed using the one dimensional elastic wave theory:

$F_{\text {calib }}(t)=E_{i} S_{i} \varepsilon_{\text {Incident }}\left(t-t_{0}\right)+E_{i} S_{i} \varepsilon_{\text {Reflected }}\left(t+t_{0}\right)$,

with $E_{i}=210 \mathrm{GPa}$ the Young's modulus, $S_{i}=8.04 \times$ $10^{-4} \mathrm{~m}^{2}$ the section of the incident bar, $t_{0}=230 \mu \mathrm{s}$ the propagation time of a compressive elastic wave between the gage and the die and $\varepsilon_{\text {Incident }}$ and $\varepsilon_{\text {Reflected }}$ the strains in the incident bar associated respectively with the incident and the reflected wave. Figure 6 depicts the evolution of the strain measured on the tube and the bar versus time while Fig. 5 shows the calculated force on the die, applied by the incident bar. A classical procedure of post processing Hopkinson bar measurements $[14,15]$ is applied to deduce these applied forces. On Fig. 5 the signal duration at half amplitude is $30 \mu \mathrm{s}$ and the maximum of the force is around $64 k N$, which is the order of magnitude of the measured blanking forces. The rise time of the force signal which is about $30 \times 10^{-3} \mathrm{~ms}$ (Fig. 6) is due to the rounded geometry of the front face of the projectile.

To calibrate our experimental device, the force signal must be related to the measured strain on the Hopkinson tube. blueThe black curve on Fig. 7 shows the strain measured on the Hopkinson tube during. This curve shows that the duration of the transmitted wave in the Hopkinson tube is similar to the force signal on the incident bar. The maximum compressive strain on the Hopkinson tube noted $\varepsilon_{\max }$ is about $320 \times 10^{-6}$. The known maximum force applied to the die and the maximum strain measured on the tube enables the calculation of a calibration ratio $K_{\max }=\frac{F_{\max }}{\varepsilon_{\max }}$ and this value is about $196 \times 10^{6} \mathrm{~N}$. Using the second projectile, the ratio becomes about $187 \times 10^{6} \mathrm{~N}$. This result shows that the coefficient $K_{\max }$ depends slightly on the loading time. These values can be compared with the calculation of $K=E_{\text {tube }} S_{\text {tube }}=130 \times 10^{6} \mathrm{~N}$ which corresponds to the case of a tube without the die perturbation.

The red dashed curve on Fig. 7 represents the strain obtained from the applied force divided by $K_{\max }$. A difference can be observed between the black and the red curves at the end of the signals. This difference can be explained by the presence of the die and the dynamics of the apparatus which induce $3 \mathrm{D}$ effects such as wave reflection inside the die.

\section{History of the Blanking Forces}

The calibration gives the elementary forces signals, $F_{\text {calib }}(t)$, and the related strain, $\varepsilon_{\text {calib }}(t)$ measured on the Hopkinson tube. The blanking force identification method approximates the measured strain $\varepsilon_{m}$ using a combination of different $\varepsilon_{\text {calib }}(t)$. The measured strain signal is decomposed in several elementary calibration strains and using the property of linearity inherent in the device, it is
Fig. 4 Diagram of the experimental calibration device

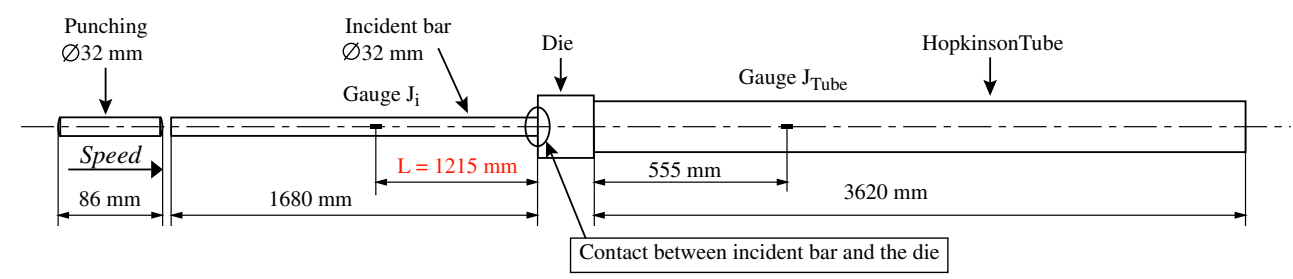


Fig. 5 Calibration force $F_{\text {calib }}$ applied on the die

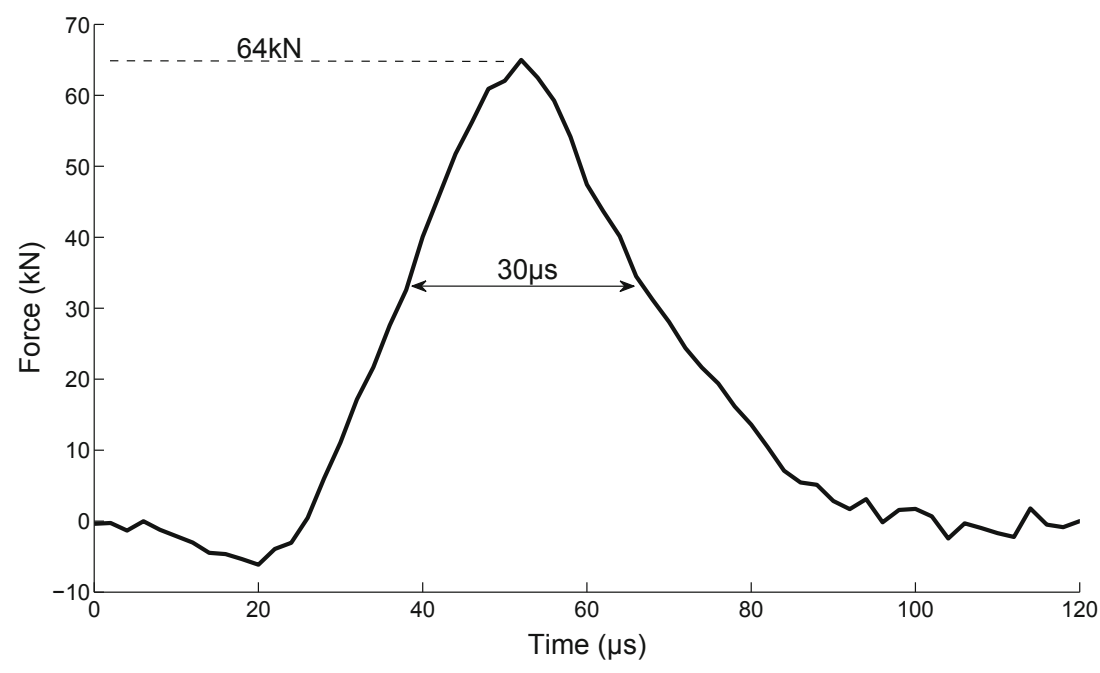

possible to estimate the related blanking force. To have a good approximation of the strain signal $\varepsilon_{m}(t)$ and therefore a good approximation of the blanking force, the calibration curve $\varepsilon_{\text {calib }}(t)$ must be improved by combination with other calibration signals. This family of calibration curves is noted $\varepsilon_{c a l i b, i}(t)$ and the associated forces $F_{\text {calib,i }}(t)$.

A temporal lag in the force generates the same temporal lag on the strain measured on the tube. A calibration curve family $\varepsilon_{c a l i b, i}(t)=\varepsilon_{c a l i b}\left(t+i \Delta t_{c}\right)$ is thus obtained by time shifting the calibration curve $\varepsilon_{c a l i b}(t)$. The time-gap $\Delta t_{c}$ between each curve is chosen equal to $1 \mu s$, the sampling time of the data acquisition. The associated forces are also $F_{\text {calib }, i}(t)=F_{\text {calib }}(t+i \Delta t)$. With this calibration curve family, strains measured on the Hopkinson tube, $\varepsilon_{m}(t)$, can be written as a linear combination of $\varepsilon_{c a l i b, i}(t)$

$\varepsilon_{m}(t)=\left(\sum_{i}^{n} \alpha_{i} \varepsilon_{\text {calib }, i}(t)\right)+r(t)$ with
$\varepsilon_{\text {calib }, i}(t)=\varepsilon_{\text {calib }}\left(t+i \Delta t_{c}\right)$

with $n$ the number of curve and $r(t)$ the residual strain.

This approach can be used because the relation between measured strain and the blanking forces is quite linear. This hypothesis can be justified experimentally during the calibration of the system. Therefore, a sum of calibration forces $F_{\text {calib,i(t) }}$ which are nearly the same as the force obtained during the blanking process is applied and if the

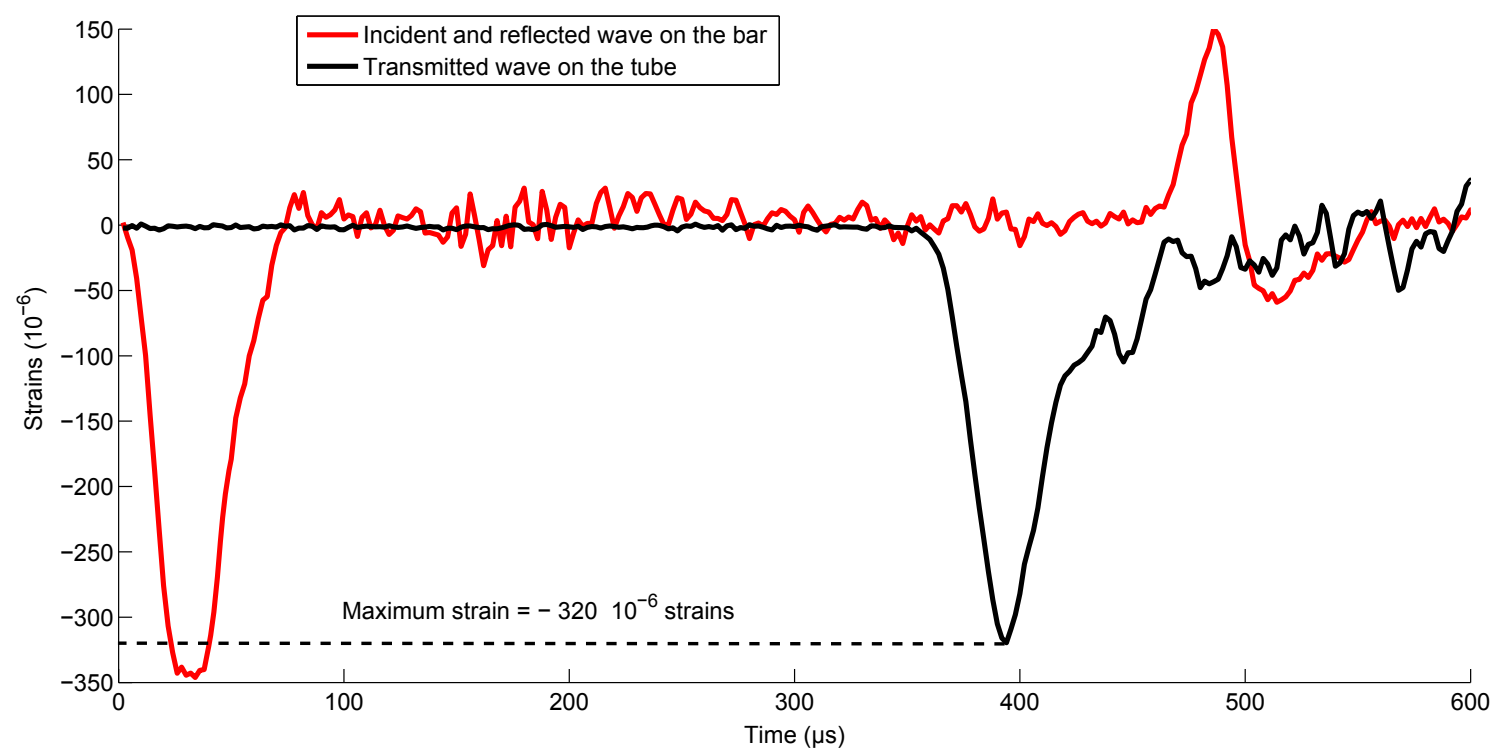

Fig. 6 Evolution of the measured strain in the tube and the bar versus time 
Fig. 7 Calibration strains on the Hopkinson tube $\varepsilon_{\text {calib }}$

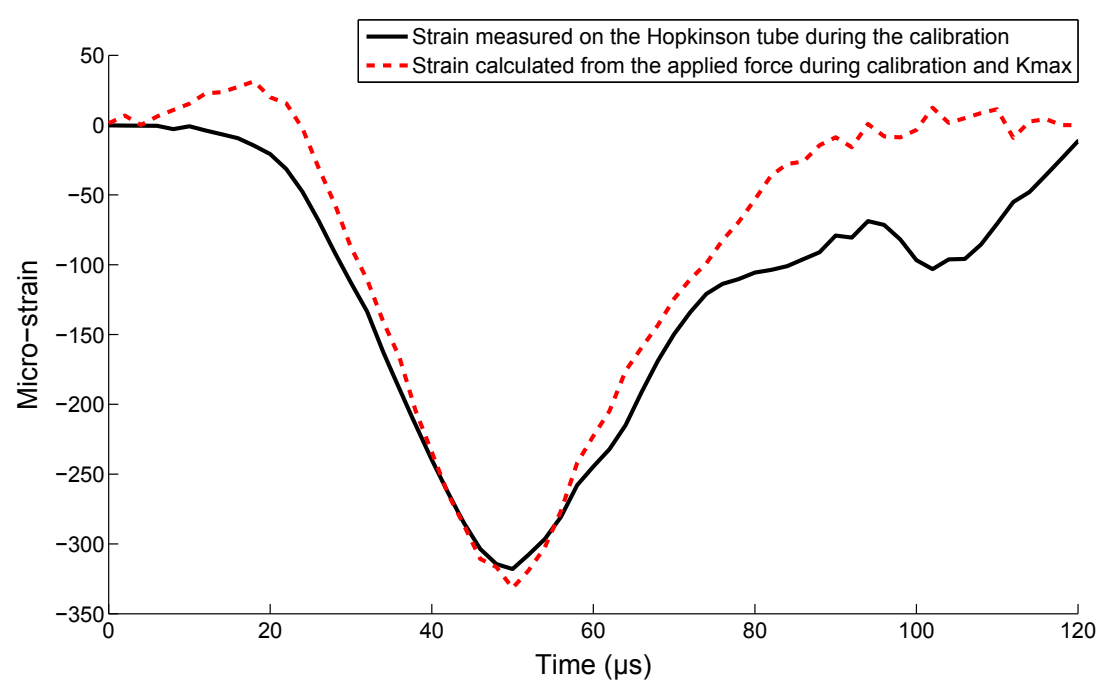

corresponding strains $\varepsilon_{i}(t)$ are known, an estimation of blanking forces $F_{m}(t)$ noted $F_{\text {recons }}$ can be reconstructed:

$F_{\text {recons }}(t)=\sum_{i}^{n} \alpha_{i} F_{\text {calib }, i}(t) \quad$ with

$F_{\text {calib }, i}(t)=F_{\text {calib }}\left(t+i \Delta t_{c}\right)$

A gap $G$ between the measurements and the strains obtained with the calibration is defined as follows:

$G=\sqrt{\frac{1}{\Delta t} \int_{t_{i}}^{t_{f}}\left(\varepsilon_{m}(t)-\sum_{i}^{n} \alpha_{i} \varepsilon_{\text {calib }, i}(t)\right)^{2} \mathrm{~d} t}$

with $\Delta t=t_{f}-t_{i}$ the measurement duration. To get the best approximation of $\varepsilon_{m}(t)$ and also the best approximation of $F_{m}(t)$ the residual $r(t)$ and the gap $G$ must be minimized. The derivative expression of equation (4) is therefore calculated and optimized $\alpha_{i}$ which minimizes the gap between $\varepsilon_{m}(t)$ and $\sum_{i} \alpha_{i} \varepsilon_{i}(t)$ are obtained. The Fig. 8 shows the result of this construction for a blanking test with a $2 \mathrm{~mm}$ the sheet metal thickness and a punching speed of $11.5 \mathrm{~ms}^{-1}$. In this case, the time-gap between each calibration curve is $12 \mu \mathrm{s}$. Only the 10 first curves are shown on the Fig. 8, multiplied by the coefficient $\alpha_{i}$ calculated with the method. The red curve represents the measurements made during the blanking test and the black one represents the sum of all curves used on the calibration. After the optimization step, it is also possible to estimate the blanking force $F_{c}(t)$ using the optimized $\alpha_{i}$ and the forces signal family $F_{i}(t)$ using equation (3).

Figure 9 also represents in red the estimation of the blanking forces with the reconstruction method for a punching speed around $11.5 \mathrm{~ms}^{-1}$, a thickness about $2 \mathrm{~mm}$ and a gap equal to $0.05 \mathrm{~mm}$. To obtain this curve, the time-gap between each calibration curve is equal to $1 \mu s$. The black curve in this figure corresponds to the forces calculated directly by multiplying the strain in the Hopkinson tube by
Fig. 8 Representation of the reconstruction of the measured strain with the calibration curve family

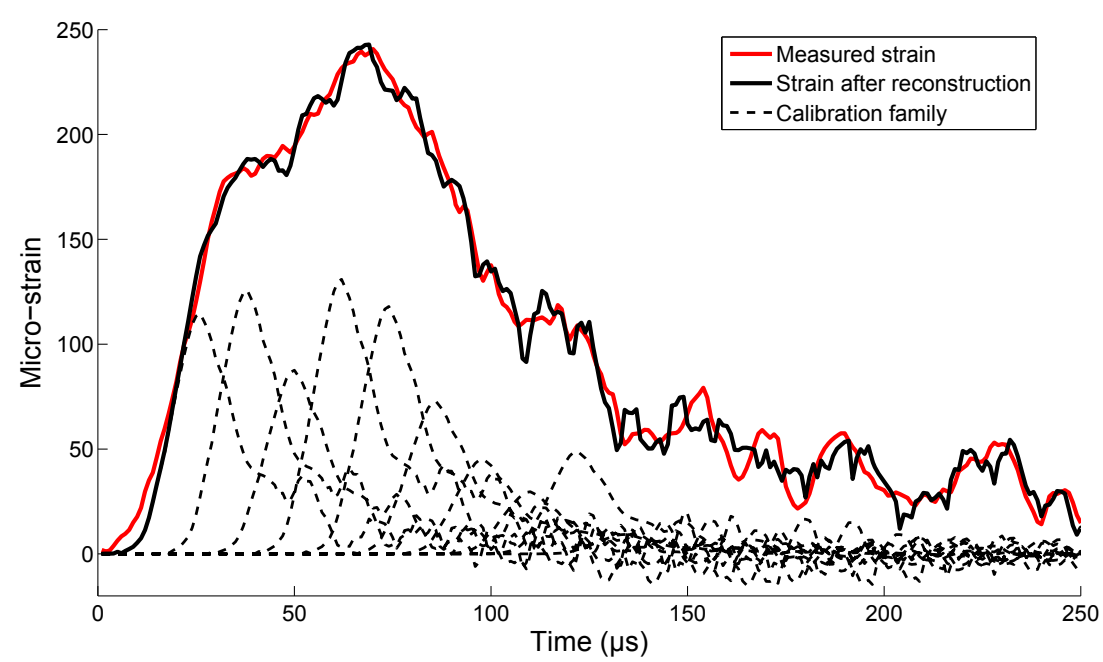


Fig. 9 Estimation of the blanking forces (C40 Steel; initial speed: $11.5 \mathrm{~ms}^{-1}$; thickness: $2 \mathrm{~mm}$; clearance: $0.05 \mathrm{~mm}$ )

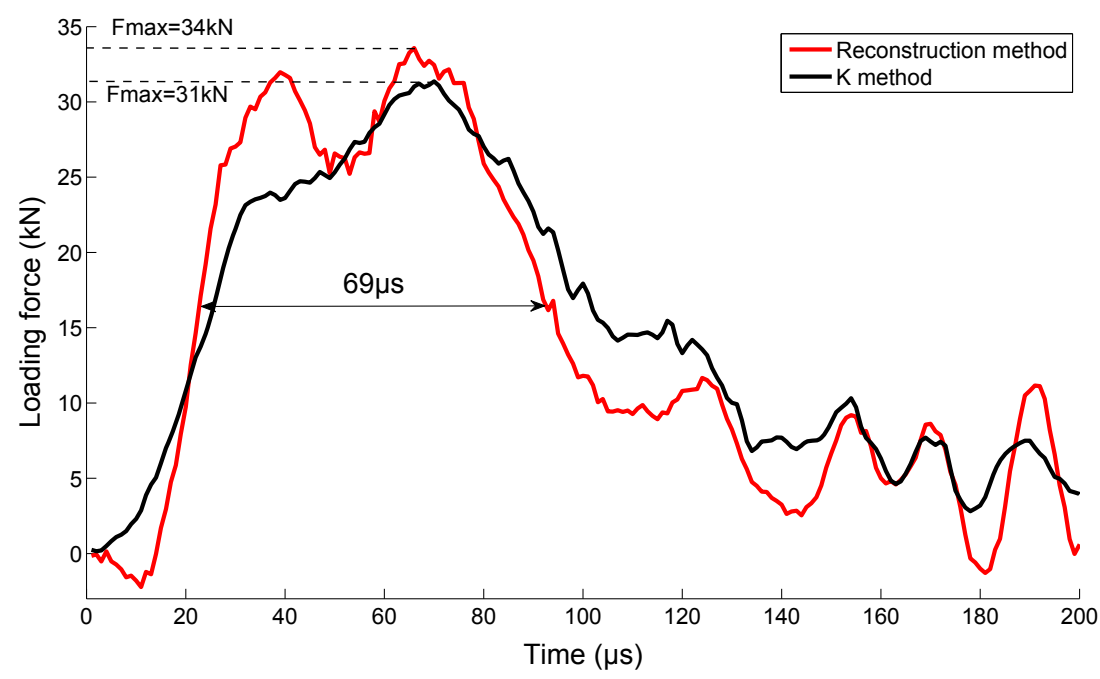

the factor $K=E_{\text {tube }} S_{\text {tube }}$ (called the " $K$ method"). For this test, the maximum force calculated with the two methods is $34 k N$ with the reconstruction method and $31 k N$ with the " $K$ method". Figure 10 shows the results of the two methods for a test using the same thickness and the same clearance but using a higher punch speed of $16.7 \mathrm{~ms}^{-1}$. The maximal blanking forces are respectively $26 k N$ and $35 k N$ obtained from the " $K$ method" and the reconstruction method. From these two tests it can be concluded that the correction of the proposed reconstruction method becomes more significant for the shorter loading duration induced by a higher blanking speed. The shape of the blanking force evolution is dependent on the punch speed: for the blanking speed of $11.5 \mathrm{~ms}^{-1}$ the blanking forces show two maxima and for the blanking speed of $16.7 \mathrm{~ms}^{-1}$ the blanking force shows only one maximum. This result can be more precisely explained by the effect of the punch geometry on the blanking forces evolution and by the complex wave propagation in the punch.

From each test, a loading duration defined as the time during which the blanking force is higher than $50 \%$ of the maximum blanking force can be estimated from the Figs. 9 and 10. For a punch speed of $11.5 \mathrm{~ms}^{-1}$ and $16.7 \mathrm{~ms}^{-1}$, the loading durations are respectively $69 \mu s$ and $44 \mu s$.

\section{Results and Discussion}

Different thicknesses of $2 \mathrm{~mm}, 3 \mathrm{~mm}$ and $4 \mathrm{~mm}$ and different punch speeds between $7 \mathrm{~ms}^{-1}$ and $18 \mathrm{~ms}^{-1}$ have been tested. For each test the maximum blanking force obtained with the reconstruction method is shown in Fig. 11. The evolution of the maximum forceversus the initial punch speed for the various thicknesses is quasi-linear. For a punch speed
Fig. 10 Estimation of the blanking forces (C40 Steel; initial speed: $16.7 \mathrm{~ms}^{-1}$; thickness: $2 \mathrm{~mm}$; clearance: $0.05 \mathrm{~mm}$ )

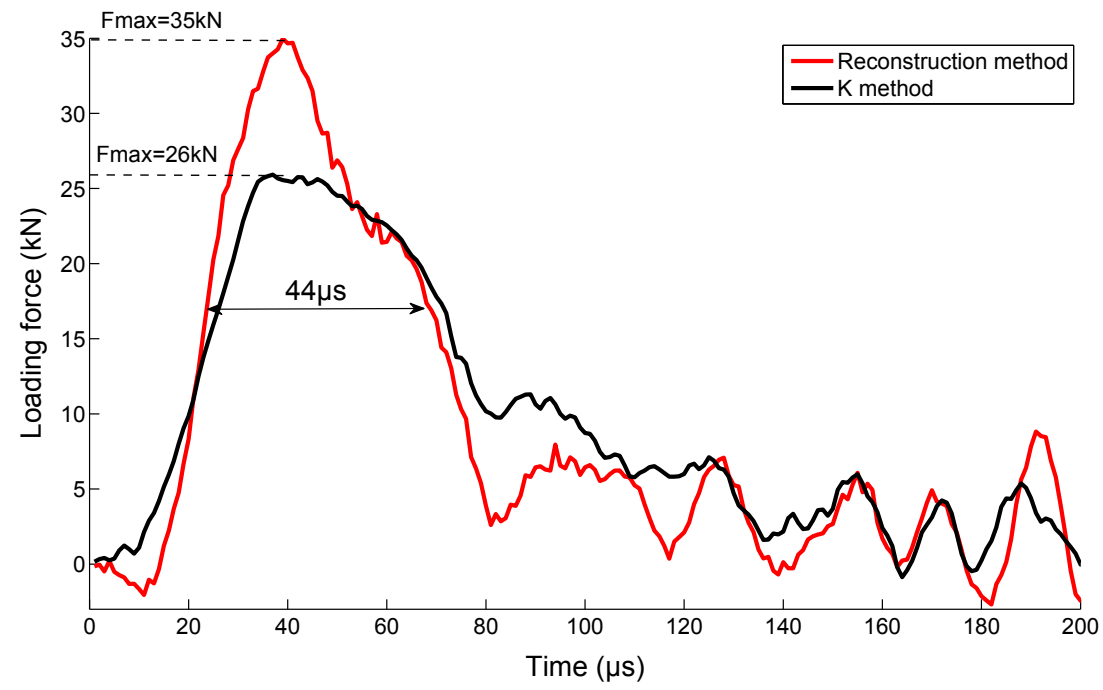


Fig. 11 Maximum loading force evolution versus punch speed

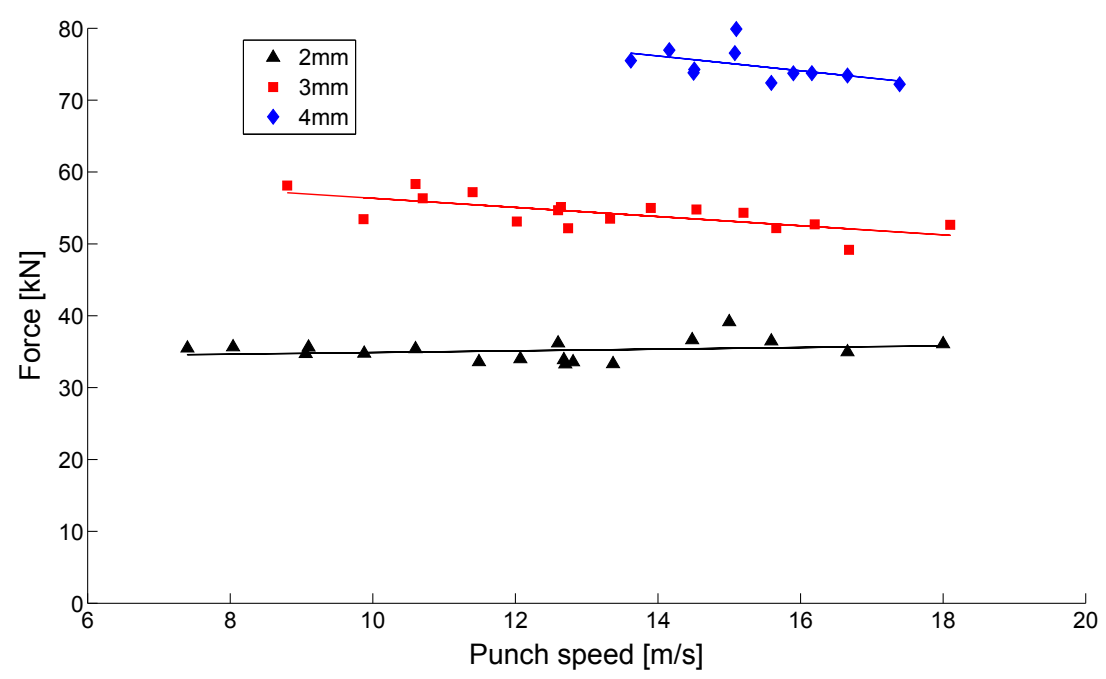

of $14 \mathrm{~ms}^{-1}$ the maximum force is equal to $34 \mathrm{kN}, 54 \mathrm{kN}$ and $76 \mathrm{kN}$ respectively for the thickness of $2 \mathrm{~mm}, 3 \mathrm{~mm}$ and $4 \mathrm{~mm}$. These blanking force values divided by two times the cross section of the specimen give blanking stresses equal to $500 \mathrm{MPa}, 529 \mathrm{MPa}$ and $558 \mathrm{MPa}$ : these values are very close. The evolution of the blanking forces according to the punch speed seems to be constant for a thickness of $2 \mathrm{~mm}$ and decreases with increasing thickness. This thickness effect has not previously been described in the literature. The reduction of the blanking forces with the punch speed is because for high punch speeds, the thermal softening of the materials plays a predominant role compared with the strain and strain rate hardening [9]. The greater the thickness of the specimen, the greater the decrease in the blanking forces with speed. For thicknesses of $3 \mathrm{~mm}$ and $4 \mathrm{~mm}$, the maximum blanking forces decrease by $0.6 \mathrm{kN}$ and $1.0 \mathrm{kN}$ when the blanking speed increases of $1 \mathrm{~ms}^{-1}$.

For each test, a characteristic time denoted $t_{c}$ can be defined as the ratio of the thickness and the initial punch speed. The Fig. 12 represents the evolution of the ratio of the loading duration and the characteristic time and shows that this ratio is very close for the different thicknesses and it slightly decreases when the blanking speed increases. So when the blanking speed increases, the drop of the blanking forces occurs earlier and therefore the fracture takes place for a lower penetration depth of the punch. These results are in agreement with work of Dowling et al. [11].

\section{Conclusion}

To better understand the high speed blanking process, an experimental device has been designed and built to match certain industrial characteristics such as punch-die clearance or tool geometry. This device works at high punch speeds, up to $25 \mathrm{~ms}^{-1}$ and allows the measurement of the punch speed evolution and the blanking forces during the process. In this study, a new method for measuring the blanking
Fig. 12 Ratio of the loading time to the characteristic time evolution versus punch speed

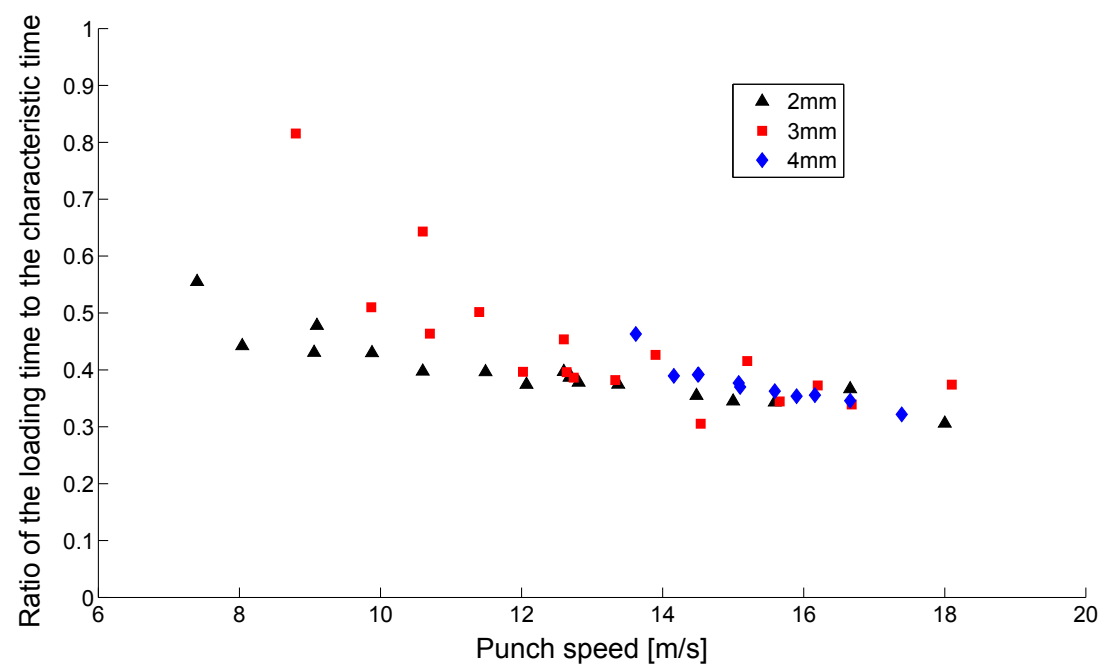


force evolution has been developed. This method is based on the Hopkinson tube method and takes into account the dynamic effects and the complex geometry of the device and in particular, of the die.

Dynamic punching tests were carried out on C40 steel specimens. Thicknesses of $2 \mathrm{~mm}, 3 \mathrm{~mm}$ and $4 \mathrm{~mm}$ and different punch speeds were used to examine the punching speed effect. For an initial punch speed of $14 \mathrm{~ms}^{-1}$ and a thickness of $3 \mathrm{~mm}$, a maximum blanking force was estimated at about $54 \mathrm{kN}$. For the $\mathrm{C} 40$ steel, the maximum force calculated with the method decreases with increasing punch speed. The loading duration evolution from the punch speed shows that the specimen fracture takes place earlier for a lower penetration depth of the punch when the punch speed increases.

Acknowledgment This study was carried out with the financial support of CETIM.

\section{References}

1. Lascoe OD (1988) Handbook of fabrication processes. ASM International

2. Nee JG (1998) Fundamentals of tool design, 4th edn. Soc Manuf Eng
3. Smith DA (1990) Die design handbook, 3rd edn. Soc Manuf Eng

4. Zener C, Hollomon JH (1944) Effect of strain rate upon plastic flow of steel. J Appl Phys 15(1):22-32

5. Johnson W, Slater RAC (1964) A comparison of the energy required for slow speed and dynamic blanking using an improved linear motor. Proc Inst Mech Eng 179(1):257

6. Johnson W, Slater RAC (1965) Further experiments in quasi-static and dynamic blanking of circular discs from various metals. Proc Inst Mech Eng 180:163

7. Johnson W, Travis FW (1965) High-speed blanking of copper. Proc Inst Mech Eng 180:197-204

8. Slater RAC, Johnson W (1967) The effects of temperature, speed and strain-rate on the force and energy required in blanking. Int $\mathrm{J}$ Mech Sci 9(5):271-276

9. Stock TAC, Wingrove AL (1971) The energy required for highspeed shearing of steel. J Mech Eng Sci 13(2):110-115

10. Rogers HC (1979) Adiabatic plastic deformation. Annu Rev Mater Sci 9:283-311

11. Dowling AR, Harding J, Campbell JD (1970) Dynamic punching of metals. J Inst Met 98:215-224

12. Zurek AK (1994) The study of adiabatic shear band instability in a pearlitic 4340 steel using a dynamic punch test. Metall Mater Trans A 25(11):2483-2489

13. Roessig KM, Mason JJ (1999) Adiabatic shear localization in the dynamic punch test, part i: Experimental investigation. Int J Plast 15(3):241-262

14. Kolsky H (1964) Stress waves in solids. J Sound Vib 1:88-110

15. Zhao H, Gary G (1995) A three dimensional analytical solution of longitudinal wave propagation in an infinite linear viscoelastic cylindrical bar. Application to experimental techniques. J Mech Phys Solids 43(8):1335-1348 